Article

\title{
Antibacterial Activity of Sulfated Galactans from Eucheuma serra and Gracilari verrucosa against Diarrheagenic Escherichia coli via the Disruption of the Cell Membrane Structure
}

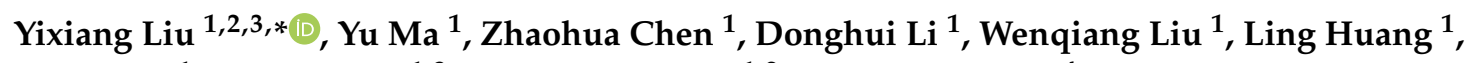 \\ Chao Zou ${ }^{1}$, Min-Jie Cao ${ }^{1,3}$, Guang-Ming Liu ${ }^{1,2}$ and Yanbo Wang ${ }^{4}$ \\ 1 College of Food and Biological Engineering, Jimei University, Xiamen 361021, Fujian, China; \\ my358108@163.com (Y.M.); zhchen@jmu.edu.cn (Z.C.); dh15589515872@163.com (D.L.); \\ lwq19950512@163.com (W.L.); 15574291255@163.com (L.H.); zouchaoknight@163.com (C.Z.); \\ mjcao@jmu.edu.cn (M.-J.C.); gmliu@jmu.edu.cn (G.-M.L.) \\ 2 Xiamen Key Laboratory of Marine Functional Food, Xiamen 361021, Fujian, China \\ 3 National \& Local Joint Engineering Research Center of Deep Processing Technology for Aquatic Products, \\ Xiamen 361021, Fujian, China \\ 4 School of Food Science and Biotechnology, Zhejiang Gongshang University, \\ Hangzhou 310018, Zhejiang, China; wangyb@mail.zjgsu.edu.cn \\ * Correspondence: lyxjmu@jmu.edu.cn; Tel.: +86-0592-6181915; Fax: +86-0592-6180470
}

Received: 12 July 2020; Accepted: 27 July 2020; Published: 29 July 2020

check for updates

\begin{abstract}
Seaweed sulfated polysaccharides have attracted significant attention due to their antibacterial activity. This work investigated the antibacterial activity and mechanism of depolymerized sulfated galactans from Eucheuma serra (E. serra) and Gracilaria verrucosa (G. verrucosa) against enterotoxigenic Escherichia coli (ETEC) K88. The results show that removing the metal ions improves the anti-ETEC K88 activity of the galactans. The fluorescence labeling study confirmed that the sulfated galactans penetrated the cell walls and eventually reached the interior of the ETEC K88. Nucleic acid staining and intracellular protein leakage were also observed, indicating the destruction of permeability and integrity of the cell membrane. Interestingly, the two polysaccharides exhibited no effect on the proliferation of the selected Gram-positive bacteria and yeast. This indicates that the cell wall structure of the microorganisms could influence the bacteriostatic activity of the sulfated polysaccharides, as well. These results suggest that the sulfated seaweed polysaccharides might have potential application value in antibacterial diarrhea.
\end{abstract}

Keywords: sulfated galactans; enterotoxigenic Escherichia coli; antibacterial activity; bacterial diarrhea; marine algae

\section{Introduction}

Enterotoxigenic Escherichia coli (ETEC) is a kind of Gram-negative bacterium that can express a variety of membrane mucins, adhere to intestinal epithelial cells, and secrete enterotoxin to cause vomiting and diarrhea [1]. This pathogen is responsible for almost 600,000 deaths every year in most underdeveloped countries and regions, and mainly include children under 5 years old [2]. In addition, ETEC is also the leading cause of diarrhea in piglets and weaned piglets, causing substantial economic losses in the pig industry [3]. At present, antibiotics remain the primary treatment for ETEC-induced diarrhea, and although this type of treatment is extremely effective and inexpensive, the long-term use of antibiotics causes bacterial resistance. Since antibiotics can also damage the intestinal probiotics, 
leading to bacterial flora disorders in the gut [4], consumers are gradually turning their attention to natural active substances.

Polysaccharides from marine algae display a variety of potential pharmacological benefits to humans, such as anti-tumor, anti-inflammatory, antioxidant, and antiviral properties [5-8]. More recently, the bacteriostatic or bactericidal activities of sulfated seaweed polysaccharides have attracted increasing attention from consumers [9]. Previous studies indicate that fucoidan, a kind of sulfated polysaccharide from Sargassum wightii and Laminaria japonica, can effectively inhibit the growth of human pathogenic bacteria, such as Vibrio cholera, Salmonella typhi, and Escherichia coli (E. coli) $[10,11]$. Furthermore, sulfated polysaccharides from Chaetomorpha aerea exhibit an inhibitory effect on Staphylococcus aureus, but not fungi [12], while it is believed that the sulfated polysaccharides from red algae, Porphyra haitanensis and Gracilaria lemaneiformis, even displayed anti-diarrheal activity in ETEC K88-infected mice [13].

The antibacterial mechanism of cationic polysaccharides with a positive charge has been studied extensively and is relatively clear. For example, chitooligosaccharides, carrying a large number of amino groups, can bind to the negatively charged cell wall of bacteria via electrostatic adsorption, leading to the destruction of membrane permeability [14]. Moreover, chitooligosaccharides can also enter the interior of bacteria, compete with positively charged nuclear proteins, destroy DNA chains, and combine with it to achieve a bacteriostatic effect [15]. Sulfated polysaccharides are obviously different from cationic ones and are known as polyanions. Furthermore, it seems that anionic polysaccharides are unlikely to bind to negatively charged microorganism surfaces through electrostatic adsorption. However, during the invasion of animal host cells by pathogenic microorganisms, the polysaccharide receptors on the bacterial surface can specifically bind to the heparin sulfate on the surfaces of these cells, denoting a type of anionic sulfated polysaccharide [16]. Consequently, it is possible that the sulfated polysaccharides specifically recognize the polysaccharide receptors on the bacterial surface. Therefore, it is hypothesized that the sulfated polysaccharides can also degrade the cell wall structure and enter the bacterial cells, resulting in the death of the bacteria.

Eucheuma serra (E. serra) and Gracilaria verrucosa (G. verrucosa) are seaweeds from the southeast coastal areas of China and are the primary raw materials for the production of carrageenan and agar productions, respectively [17]. Previous studies have found that depolymerized sulfated galactans from both E. serra and G. verrucosa exhibited an inhibitory effect on diarrheagenic ETEC K88 [18]. This study investigated how the anti-ETEC K88 activity of sulfated galactans is enhanced by metal ion desorption since algae are responsible for enriching seawater with metal ions. More importantly, to further understand the antibacterial mechanism of the sulfated polysaccharides, a fluorescence labeling study was employed to observe their penetration into the cell walls of ETEC K88. Additionally, the influence of the cell wall structure of the microorganisms on their bacteriostatic activity was also considered by comparing the inhibitory differences on Gram-positive bacteria and fungi.

\section{Results and Discussion}

\subsection{Removing the Metal Ions from Sulfated Galactans}

The electronegative properties of sulfated polysaccharides determine their strong adsorption capacity of metal ions in seawater [19]. Therefore, it was necessary to improve the biological activity of the sulfated polysaccharides via the desorption of metal ions. Figure 1A shows that, at the beginning, the conductivity of the first filtrate of the E. serra sulfated polysaccharide (ESP) and G. verrucosa sulfated polysaccharide (GSP) solutions were 3060 and $2587 \mu \mathrm{s} / \mathrm{cm}$, respectively. The conductivity of the filtrate was close to zero after eight ultrafiltration (dilution ratio was 8) repetitions, which was, therefore, used during the subsequent experiments to remove the metal ions from the polysaccharides. Figure $1 \mathrm{~B}$ indicates that the ash content in ESP and GSP remained high at $17.8 \%$ and $13.2 \%$, respectively, after ultrafiltration in the absence of a metal ion chelating agent in the eluent. However, the ash content in polysaccharides significantly $(p<0.05)$ decreased when the added ethylenediaminetetraacetic acid 
(EDTA) concentration was increased. When the EDTA concentration reached $1 \times 10^{-2} \mathrm{~mol} / \mathrm{L}$, the ash content in ESP and GSP decreased to $8.2 \%$ and 6.7\%, respectively (Figure 1B). At the same time, the sulfate content of polysaccharides increased slightly after metal ion removal. As shown in Figure 1C, under the condition of $1 \times 10^{-2} \mathrm{~mol} / \mathrm{L}$ EDTA, the sulfate group contents of ESP and GSP were increased from $28.5 \pm 0.6 \%$ and $14.6 \pm 0.2 \%$ to $30.0 \pm 0.6 \%$ and $15.4 \pm 0.5 \%$, respectively.
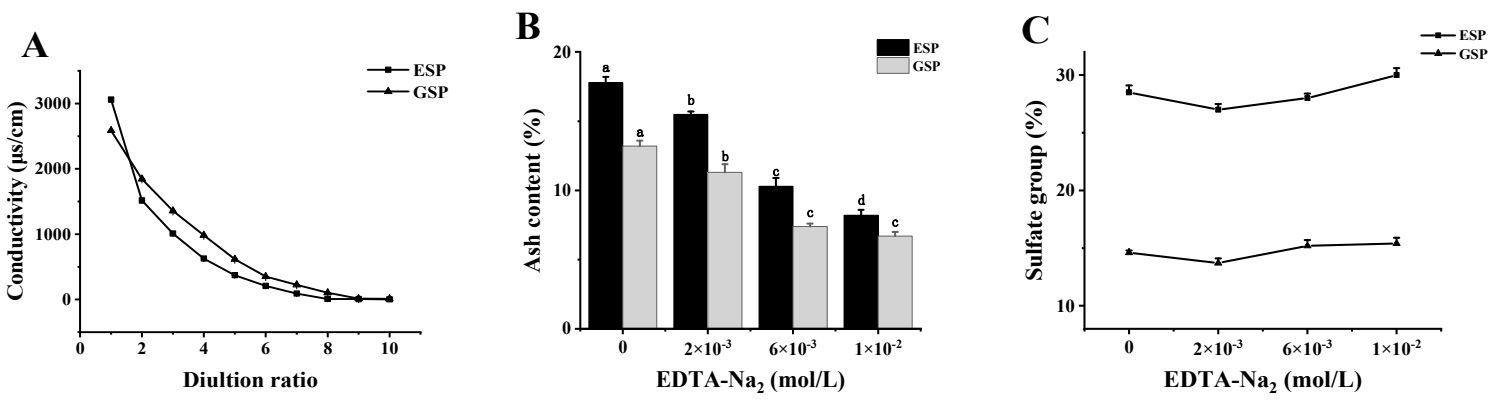

Figure 1. The effect of EDTA disodium combined with ultrafiltration technology on the desorption of metal ions in sulfated polysaccharides: (A) the conductivity changes in the ultrafiltration filtrate; (B) the influence of EDTA disodium on the ash content in ESP and GSP; and (C) the changes of sulfate group after metal ion removal. Data are expressed as mean $\pm \operatorname{SD}(n=3)$. Different letters indicate significant differences $(p<0.05)$.

The changes of above metal elements in the polysaccharides before and after desorption were investigated and the results are shown in Table 1 . The results show that the $\mathrm{Mg}^{2+}$ and $\mathrm{Ca}^{2+}$ content in ESP and GSP were relatively high, exceeding 5000 and $1500 \mathrm{mg} / \mathrm{kg}$, respectively. In addition, metal elements, such as Fe, Mn, and Zn, were also discovered in the marine sulfated polysaccharides. Metal ion removal reduced the $\mathrm{Mg}^{2+}$ content in ESP and GSP by $48 \%$ and 39\%, respectively, while a corresponding decrease of 806.4 and $610.2 \mathrm{mg} / \mathrm{kg}$ was evident in the $\mathrm{Ca}^{2+}$ content levels. Therefore, it was apparent that combining metal ion chelating agents with ultrafiltration technology could effectively remove metal ions from marine polysaccharides.

Table 1. The changes in the different metal elements in the polysaccharides after metal ion removal.

\begin{tabular}{cccccc}
\hline \multirow{2}{*}{ Items } & \multicolumn{5}{c}{ Metal Elements (mg/kg) } \\
\cline { 2 - 6 } & $\mathbf{M g}$ & Ca & Fe & Mn & Zn \\
\hline ESP & $5016.2 \pm 78.2$ & $4307.4 \pm 49.6$ & $356.7 \pm 12.2$ & $93.3 \pm 2.2$ & $36.7 \pm 0.5$ \\
F-ESP & $2643.7 \pm 53.6$ & $806.4 \pm 25.4$ & $234.9 \pm 10.6$ & - & $19.5 \pm 0.3$ \\
GSP & $5615.4 \pm 81.3$ & $1690.8 \pm 36.1$ & $79.1 \pm 3.4$ & $62.8 \pm 1.3$ & $33.2 \pm 0.3$ \\
F-GSP & $3477.7 \pm 62.5$ & $610.2 \pm 21.3$ & $41.7 \pm 1.7$ & - & - \\
\hline
\end{tabular}

"-" means not detected; "F-ESP" means the filtered ESP by ultrafiltration; "F-GSP" means the filtered ESP by ultrafiltration.

\subsection{Depolymerization of Sulfated Galactans}

After degradation, the microstructure of the sulfated polysaccharides was observed using scanning electron microscopy (SEM). As shown in Figure 2, both ESP and DSP displayed a dense, flat appearance. After high-temperature and high-pressure treatment, the microstructure of the polysaccharides showed a visible change where the flaky structure was broken into porous flocculent. In previous research, an increase in reducing sugar and a decrease in viscosity were evident after the sulfated polysaccharides were hydrolyzed in high-temperature and high-pressure conditions [18]. 

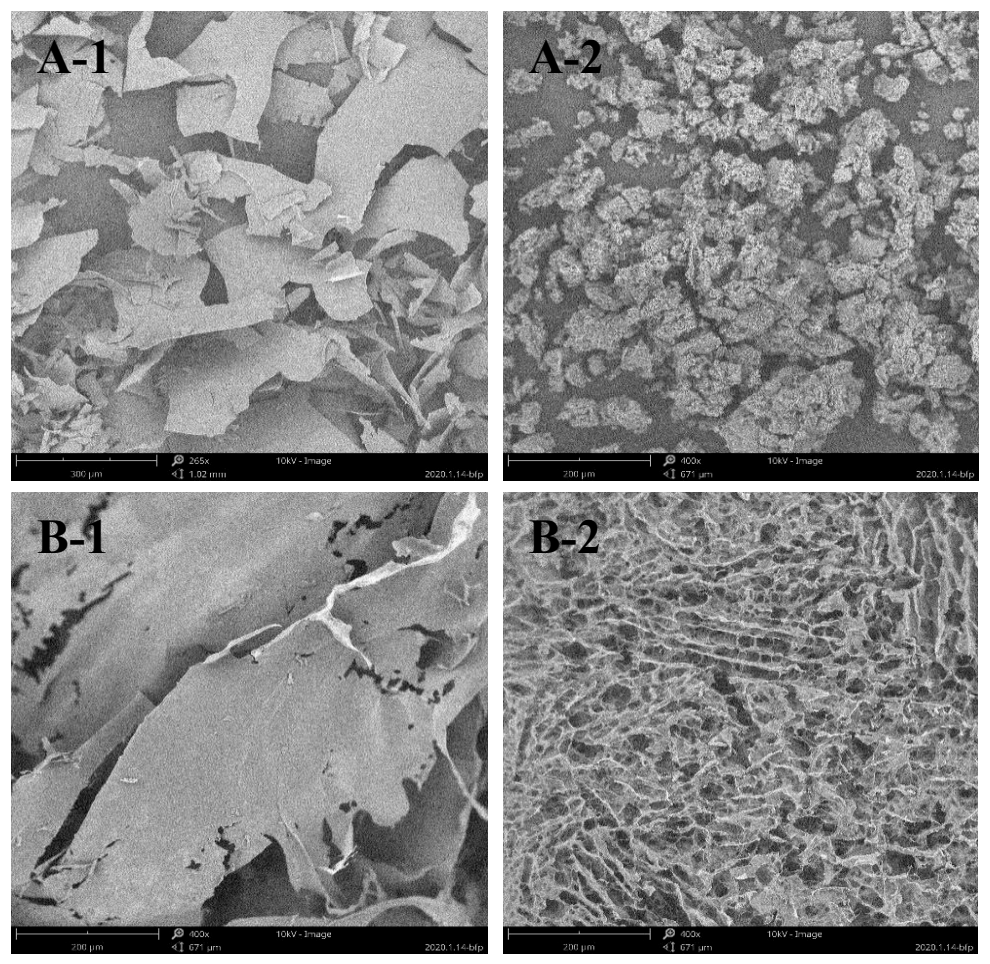

Figure 2. SEM observation of: the microstructure of the original long-chain sulfated polysaccharides (A-1 and B-1); and the depolymerized sulfated polysaccharides (A-2 and B-2).

\subsection{The Effect of Metal Ion Removal on Antimicrobial Activity}

The antibacterial activity of the polysaccharides against ETEC K88 was determined using the plate smearing method and the liquid turbidity method. Figure $3 \mathrm{~A}-\mathrm{D}$ shows that no obvious bacteriostatic effect was observed in the unhydrolyzed sulfated polysaccharides before or after metal ion removal. However, when the sulfated galactans from E. serra and G. verrucosa were degraded, the number of ETEC-K88 colonies on the medium were significantly reduced. Furthermore, only depolymerized sulfated galactans with the molecular weight $(\mathrm{MW}) \leq 6.0 \mathrm{kDa}$ displayed inhibitory effect on ETEC-K88, which is consistent with the results of a previous study [11]. Interestingly, fewer ETEC-K88 colonies were present on the medium when the depolymerized polysaccharides were exposed to the desorption of metal ions. The effect of metal ion removal on the antibacterial activity of the depolymerized polysaccharides was further verified using the liquid turbidity method (Figure 3E,F). After incubation for $24 \mathrm{~h}$, the absorbance of the bacterial suspension at $600 \mathrm{~nm}$ gradually decreased when the depolymerized polysaccharide concentration before and after metal ion removal increased from 2.0 to $10.0 \mathrm{mg} / \mathrm{mL}$. Compared with depolymerized ESP (D-ESP) without metal ion removal, the lower $(p<0.05)$ turbidity of the bacterial suspension appeared in the desalinized group ranging from 6.0 to $10.0 \mathrm{mg} / \mathrm{mL}$. For depolymerized GSP (D-GSP), the desalinized group also exhibited better $(p<0.05)$ antibacterial activity at $10.0 \mathrm{mg} / \mathrm{mL}$. 

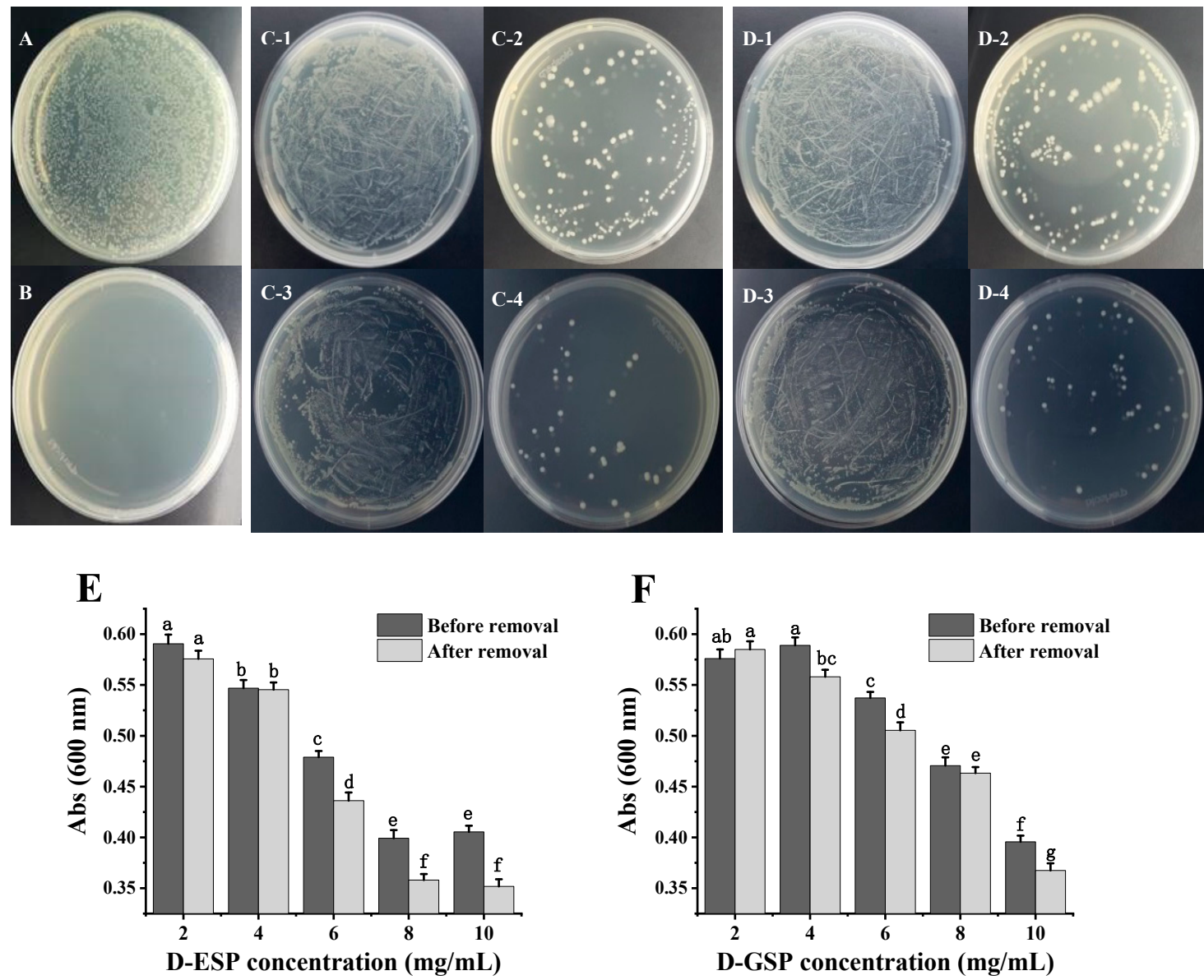

Figure 3. The antibacterial activity of sulfated polysaccharides against ETEC K88 based on the plate smearing method and liquid turbidity method: (A) the negative control ( $0.85 \% \mathrm{NaCl}$ saline); (B) positive control (0.05 mg/mL kanamycin); (C-1) ESP and (C-2) D-ESP before metal ion removal; (C-3) ESP after metal ion removal; (C-4) D-ESP after metal ion removal; (D-1) GSP and (D-2) D-GSP before metal ion removal; (D-3) GSP after metal ion removal; (D-4) D-GSP after metal ion removal; (E) the antibacterial activity of D-ESP determined via the liquid turbidity method; and (F) the antibacterial activity of D-GSP determined with the liquid turbidity method. The polysaccharide concentration for the plate smearing method is $7.5 \mathrm{mg} / \mathrm{mL}$. Data are expressed as mean $\pm \mathrm{SD}(n=3)$. Different letters indicate significant differences $(p<0.05)$.

Table 2 shows that, after desalination, the minimal inhibitory concentration (MIC) and minimal bactericidal concentration (MBC) values of D-ESP decreased from $10.0 \mathrm{~L}$ to $8.0 \mathrm{mg} / \mathrm{mL}$ and from 25.0 to $12.5 \mathrm{mg} / \mathrm{mL}$, respectively, while the MIC value of D-GSP further decreased from 12.5 to $10.0 \mathrm{mg} / \mathrm{mL}$. According to previous studies, metal ion removal enhanced the antioxidant activity of the sulfated polysaccharides from Ascophyllum nodosum, while the inhibitory effect of tea polysaccharides on $\alpha$-glucosidase was also higher $[20,21]$. In this study, it seemed that both sugar chain degradation and metal ion removal effectively improved the antibacterial activity of sulfated polysaccharides against ETEC K88.

Table 2. The effect of metal ion removal on the antibacterial activity of sulfated polysaccharides.

\begin{tabular}{ccccc}
\hline \multirow{2}{*}{ Test Items } & \multicolumn{2}{c}{ D-ESP } & \multicolumn{2}{c}{ D-GSP } \\
\cline { 2 - 5 } & Before Removal & After Removal & Before Removal & After Removal \\
\hline MIC $(\mathrm{mg} / \mathrm{mL})$ & 10.0 & 8.0 & 12.5 & 10.0 \\
MBC $(\mathrm{mg} / \mathrm{mL})$ & 25 & 12.5 & 25.0 & 25.0 \\
\hline
\end{tabular}




\subsection{Observation of the Polysaccharides Entering the Bacterial Cells}

It is believed that low MW chitosan can quickly enter E. coli cells via electrostatic adsorption, destroying the cell membrane structure [22]. However, due to the electronegativity of the bacterial cell wall, it is not clear whether anionic polysaccharides such as sulfated polysaccharides can bind and pass through it. The fluorescent dye 2-aminoacridone (2-AMAC) itself cannot penetrate the bacterial cell walls but can bind to the reducing end of the polysaccharide by decreasing the amination reaction [23]. Consequently, in this work, 2-AMAC was selected as the fluorescent label probe to investigate whether D-ESP or D-GSP can enter the cell interior of ETEC K88. Figure 4 indicates that, after the fluorescence-labeled sulfated polysaccharides were co-cultured with ETEC-K88 for $30 \mathrm{~min}$, a distinct green fluorescence was observed in the cell interior using a fluorescent microscope. This result confirms that, as an anionic polymer, sulfated polysaccharides could penetrate cell walls to enter the cell interior of bacteria.
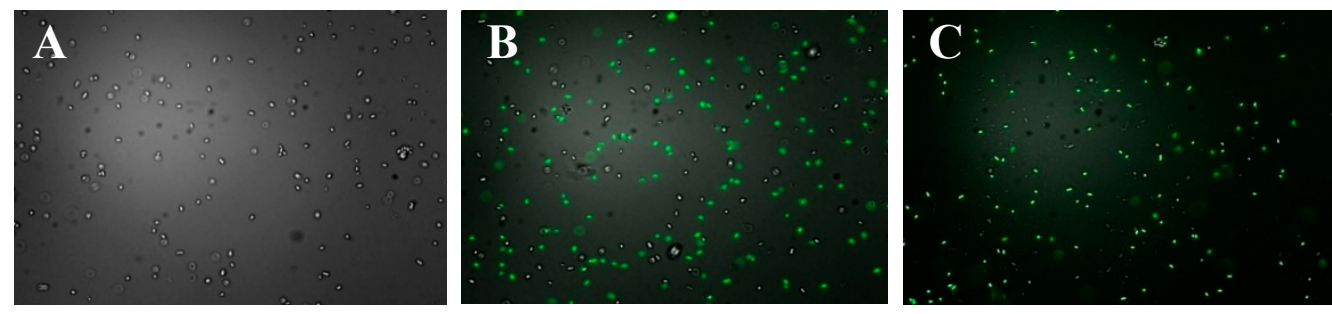

Figure 4. Observation of the D-ESP and D-GSP entering the cell interior of ETEC K88 using a fluorescent microscope (800×): (A) ETEC-K88 treated with 2-AMAC; (B) ETEC-K88 treated with 2-AMAC-labeled D-ESP; and (C) ETEC-K88 treated with 2-AMAC-labeled D-GSP.

\subsection{The Effect of Depolymerized Sulfated Galactans on Cell Membrane Permeability}

Based on the results obtained regarding the entrance of sulfated polysaccharides into the ETEC K88 bacterial cells, the changes in the permeability of the cell membrane were further investigated during subsequent experiments. As a kind of nucleic acid fluorescent probe, propidium iodide (PI) can enter the bacterial cell interior when the cell membrane is damaged to combine with DNA molecules, resulting in the cells of the bacteria fluorescing red when viewed under an optical microscope [24]. Therefore, this work employed a PI fluorescence probe to reflect the membrane permeability of ETEC-K88 after polysaccharide treatment. Figure 5 indicates that only a few red cells were observed in the control group (without polysaccharide treatment). However, after D-ESP and D-GSP treatments at one or two times the MIC concentration, many ETEC K88 cells showing red fluorescence were observed in the field of vision. The present result is similar to an earlier report that the fluorescence intensity of E. coli treated with a 2MIC concentration of anthocyanin exceeded that of the blank group [24]. At the same time, it was also obvious that, compared with the 1MIC concentration, more red cells were uncovered when a $2 \mathrm{MIC}$ concentration of polysaccharides was used. These results demonstrate that sulfated polysaccharides could destroy the cell membrane permeability of ETEC-K88. 

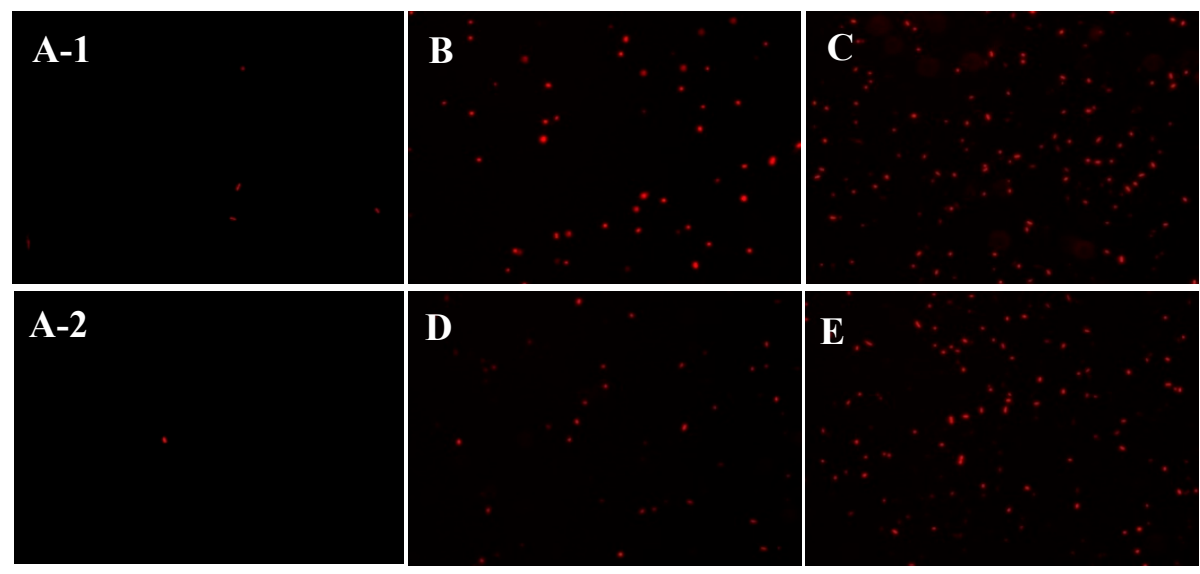

Figure 5. The effect of D-ESP and D-GSP on the cell membrane permeability of ETEC K88 under a fluorescent microscope $(800 \times)$ : (A-1,A-2) the control groups; (B) ETEC K88 treated with a 1MBC concentration of D-ESP; (C) ETEC K88 treated with a 2MBC concentration of D-ESP; (D) ETEC K88 treated with a $1 \mathrm{MIC}$ concentration of D-GSP; and (E) ETEC K88 treated with a 2MIC concentration of D-ESP.

\subsection{Analysis of the Cell Membrane Integrity}

When the integrity of the microbial cell membrane is destroyed, proteins, nucleic acids, and other large molecules are released from the cell [25]. Therefore, in this study, the effect of sulfated polysaccharides on the cell membrane integrity of ETEC K88 was determined by analyzing intracellular protein release. Figure 6 indicates that Lanes 1, 4, and 7 represent the culture samples of ETEC K88 after sterile water or polysaccharide treatment for $1 \mathrm{~h}$, while no obvious protein bands were observed. When the polysaccharide treatment time was extended to $3 \mathrm{~h}$, obvious protein bands at $35 \mathrm{KDa}$ were evident in Lanes 5 and 8, compared with the control group (Lane 2). This molecular weight was consistent with that of membrane-bound lytic transglycosylase (Mlt), which is present in the plasma membrane and outer membrane of E. coli [26]. It is believed that when the Mlt is released from the intracellular to the extracellular, it can act as a lysozyme and hydrolyze the murein polymer of the bacterial cell wall [26]. However, the protein band at $40 \mathrm{KDa}$ was also observed after the D-GSP treatment. Unfortunately, the possible information represented by the protein is still unclear. In addition, it is also necessary to further study why different sulfated polysaccharide treatment may lead to different protein leakage of ETEC K88. In conclusion, both the sulfated polysaccharides, namely D-ESP and D-GSP, caused significant destruction to the cell membrane of ETEC K88, leading to intracellular protein leakage. The results are consistent with the findings of earlier studies. Zhang et al. (2017) found that the soluble proteins in the E. coli culture increased after treating with polysaccharides from Cordyceps cicadae [27]. Previous studies also confirmed that the sulfated polysaccharides could cause an increase in nucleic acid levels of the ETEC K88 culture [11,18].

\subsection{Sensitivity to Different Microorganisms}

Due to the differences in the cell wall structure of different microorganisms, this study further compared the sensitivity of sulfated polysaccharides to Gram-positive bacteria (including three intestinal probiotics and S. aureus ATCC 29213) and yeast (Saccharomyces cerevisiae BY4741). Figure 7 shows that when exposed to MBC concentrations (12.5 mg/mL for D-ESP and $25.0 \mathrm{mg} / \mathrm{mL}$ for D-GSP), both D-ESP and D-GSP exhibited no apparent inhibitory effect on the growth of intestinal probiotics, Lactobacillus rhamnosus ATCC 53103, Bacillus coagulans ATCC 7050, and Bacillus subtilis CMCC 63501, as well as yeast Saccharomyces cerevisiae BY4741. However, the proliferation of ETEC K88 was completely suppressed for both D-ESP and D-GSP. This may be attributed to the different cell wall structures of the microorganisms. It is believed that the outer cell wall of Gram-negative bacteria contains lipoproteins and that the peptidoglycan layer is thinner than that of Gram-positive bacteria. However, 
not only do the cell walls of Gram-positive bacteria have a much thicker peptidoglycan layer, but also the presence of phosphoric acid causes Gram-positive bacteria to be more negatively charged than Gram-negative bacteria $[28,29]$. In yeast, polysaccharides find it difficult to bind to the polysaccharide receptors on the cell surface and to penetrate the cell wall due to the wall's thickness and the deeply encapsulated membrane proteins by dextran [24]. The results reveal that both D-ESP and D-GSP could selectively inhibit the proliferation of ETEC K88 but not intestinal probiotics, indicating their potential for anti-diarrheal application.

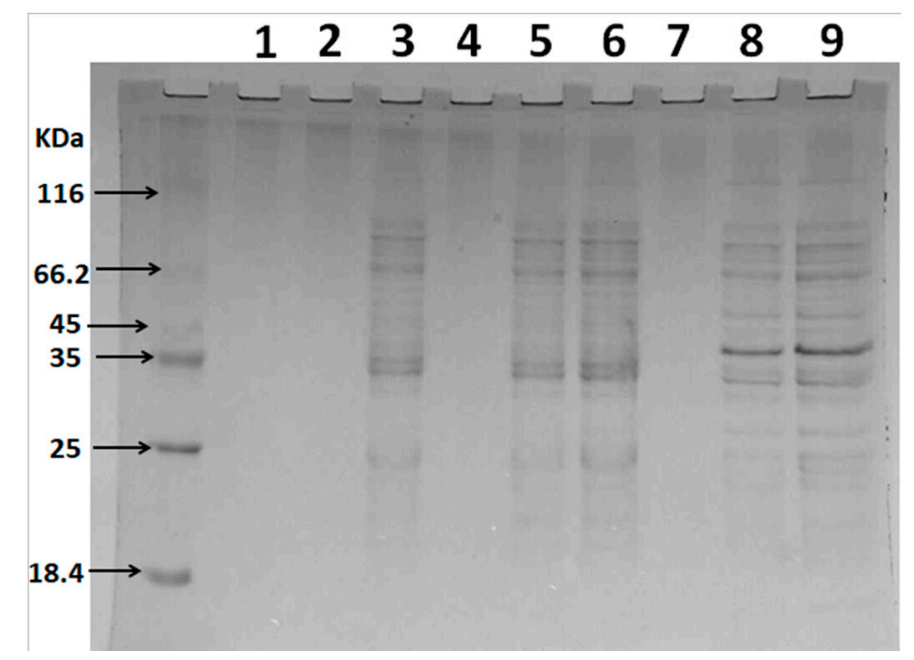

Figure 6. The effect of D-ESP and D-GSP on the intracellular protein leakage of ETEC-K88 based on SDS-PAGE analysis: Lanes 1-3, control groups (sterile water, 1, 3, and $5 \mathrm{~h}$, respectively); Lanes 4-6, ETEC K88 treated with a $1 \mathrm{MBC}$ concentration of D-ESP for 1, 3, and $5 \mathrm{~h}$ respectively; and Lanes 7-9, ETEC K88 treated with a 1MBC concentration of D-GSP for 1, 3, and $5 \mathrm{~h}$, respectively.

A
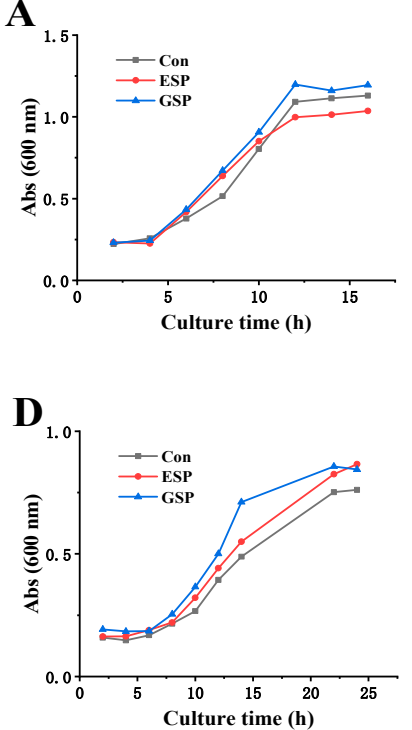

B

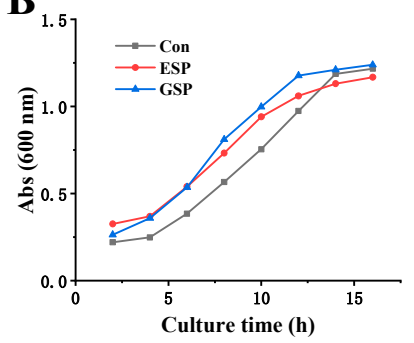

$\mathbf{E}$

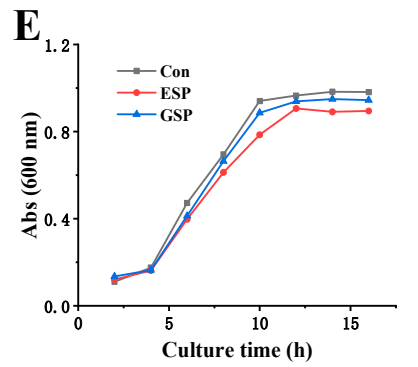

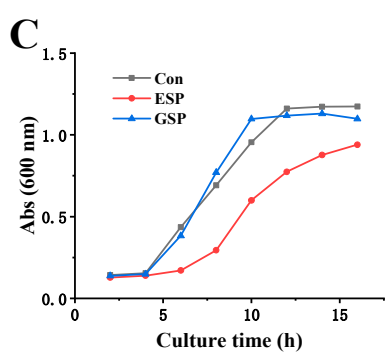

$\mathbf{F}$

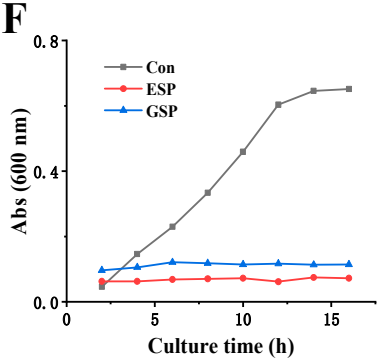

Figure 7. The effect of polysaccharide on the growth curve of intestinal bacteria: (A) Lactobacillus rhamnosus ATCC 53103; (B) Bacillus coagulans ATCC 7050; (C) Bacillus subtilis CMCC 63501; (D) Saccharomyces cerevisiae BY4741; (E) S. aureus ATCC 29213; and (F) ETEC K88. 


\section{Materials and Methods}

\subsection{Chemical Reagents and Materials}

The metal ion standard solutions were purchased from the National Institute of Metrology (Beijing, China). Gelatin was purchased from the Sangon Biotech Corporation Ltd. (Shanghai, China). The brain heart infusion (BHI) was purchased from Shanghai Gaochuang Chemical Technology Ltd. (Shanghai, China). Deionized water was produced using a Milli-Q unit (Millipore, Bedford, MA, USA). Other analytical reagent-grade reactants were purchased from the China National Pharmaceutical Industry Corporation Ltd. (Shanghai, China).

\subsection{The Isolation and Purification of Sulfated Galactans}

The collection and pretreatment of red algae E. serra and G. verrucosa were performed according to the methods used in an earlier study [18]. The sulfated galactans from E. serra were extracted and isolated based on previous studies [18,30]. Briefly, $100 \mathrm{~g}$ of the dried E. serra powder were macerated in water at $50{ }^{\circ} \mathrm{C}$ for $4 \mathrm{~h}$. Then, the E. serra syrup was filtered through filter cloth, concentrated to $1 / 4$ th of the original volume, cooled, and precipitated overnight with three volumes of ethanol at $4{ }^{\circ} \mathrm{C}$. The precipitate was collected via centrifugation ( $5000 \mathrm{r} / \mathrm{min}, 10 \mathrm{~min}$ ), washed three times with $75 \%$ ethanol, dehydrated, and lyophilized to obtain a dried crude ESP.

The sulfated polysaccharides were obtained from G. verrucosa as described previously [18,31]. Briefly, the G. verrucosa powder was extracted twice with $50{ }^{\circ} \mathrm{C}$ water at a mass volume ratio of 1:40 $(w / v)$ for $4 \mathrm{~h}$ and filtered through a filter cloth. The combined extracts were concentrated to $1 / 4$ th of initial volume in a rotary evaporator at reduced pressure at $60^{\circ} \mathrm{C}$. Then, $95 \%(v / v)$ ethanol was added to the concentrated supernatants, while being constantly stirred to acquire a final concentration of $40 \%(v / v)$ ethanol. The solution was left overnight at $4{ }^{\circ} \mathrm{C}$ and centrifuged at $5000 \mathrm{r} / \mathrm{min}$ for $10 \mathrm{~min}$. The supernatant was again added to $95 \%(v / v)$ ethanol to obtain a final concentration of $80 \%(v / v)$ ethanol and kept overnight at $4{ }^{\circ} \mathrm{C}$. The polysaccharides were collected via centrifugation using the same values as above and washed three times with $75 \%(v / v)$ ethanol, dehydrated, and lyophilized to obtain a dried crude GSP.

The crude sulfated polysaccharides were dissolved in distilled water to deproteinize them using the Sevag method [11]. The polysaccharide solution and the Sevag reagent (chloroform/n-butanol 4:1, $v / v$ ) were mixed (polysaccharide solution/Sevag reagent 5:1, v/v) and thoroughly shaken for $30 \mathrm{~min}$, after which it was centrifuged to remove the denatured proteins. This process was repeated five times. After the precipitate was collected and lyophilized, the crude polysaccharide powders were kept in a glass desiccator at room temperature until use.

\subsection{The Desorption of Metal Ions from the Polysaccharides}

Based on the ultrafiltration technology, EDTA disodium was selected as the chelating agent for the removal of the metal ions absorbed on the sulfated galactans [32]. The crude polysaccharides were weighed and dissolved in distilled water at a final concentration of $0.5 \%(w / v)$. Then, acetic acid was added to the polysaccharide solution, and the $\mathrm{pH}$ adjusted to 5.0, after which the EDTA disodium was added at different concentrations. The solution was stirred $(1200 \mathrm{r} / \mathrm{min})$ at room temperature for $30 \mathrm{~min}$ and filtered using $4 \mathrm{kDa}$ ultrafiltration membrane. During the ultrafiltration process, the conductivity of the filtrate was measured. When the conductivity value stabilized, the ultrafiltration was ceased, and the concentrated polysaccharide solution was lyophilized. The content of the polysaccharide sulfate group was determined using the gelatin barium chloride method [33], while the ash content was established with the burning weighing method [34]. The content of different metal ions $\left(\mathrm{Mg}^{2+}\right.$, $\mathrm{Ca}^{2+}, \mathrm{Fe}^{2+}, \mathrm{Mn}^{2+}$, and $\mathrm{Zn}^{2+}$ ) was detected with atomic absorption spectrophotometry [35]. 


\subsection{The Depolymerization of the Sulfated Galactans}

According to a previous report, a high-temperature and high-pressure technique were used to degrade the polysaccharides during this study [11]. The polysaccharides containing $30 \%(w / w)$ deionized water was hydrolyzed in an autoclave reactor (Shanghai Boxun Industry \& Commerce Co. Ltd. Medical Equipment Factory, Shanghai, China) at $121^{\circ} \mathrm{C}$ and $0.103 \mathrm{MPa}$ for $40 \mathrm{~min}$. Then, the depolymerized products were dissolved in deionized water and fractionated via ultrafiltration. The fractions with $\mathrm{MW} \leq 6 \mathrm{kDa}$ were collected, freeze-dried, and stored in a glass dryer at room temperature until use. The morphological changes of D-ESP $(\mathrm{MW} \leq 6 \mathrm{kDa})$ and D-GSP $(\mathrm{MW} \leq 6 \mathrm{kDa})$ were observed using SEM (S-4800, Hitachi Corporation of Japan, Tokyo, Japan).

\subsection{Bacterial Strains and Culture Conditions}

A standard strain of Gram-negative ETEC K88 (CN-3-321) was purchased from Beijing Biobw Biotechnology Co., Ltd. (Beijing, China). Lactobacillus rhamnosus ATCC 53,103 was obtained from Valio Ltd. (Helsinki, Finland). Saccharomyces cerevisiae BY4741 was provided by Euroscarf (Oberursel, Germany). S. aureus ATCC 29213, Bacillus coagulans ATCC 7050, and Bacillus subtilis CMCC 63,501 were purchased from the China Industrial Microbial Species Preservation and Management Center (Beijing, China). Lactobacillus rhamnosus ATCC 53,103 and Bacillus coagulans ATCC 7050 were cultured in MRS liquid medium. S. aureus ATCC 29213, Bacillus subtilis CMCC 63501, and ETEC K88 were cultured in LB liquid medium. Saccharomyces cerevisiae BY4741 was cultured in YPD liquid medium.

\subsection{Antibacterial Assay}

The antibacterial activity of D-ESP and D-GSP against ETEC K88 was determined using both the plate smearing method and the liquid turbidity method [36,37]. First, the aqueous polysaccharide solutions were added to the sterilized nutrient agar before solidification, to obtain the final polysaccharide concentration of $7.5 \mathrm{mg} / \mathrm{mL}$. After cooling, $100.0 \mu \mathrm{L}$ of the ETEC K88 suspension $\left(10^{6} \mathrm{CFU} / \mathrm{mL}\right)$ were spread onto the surface of the polysaccharide samples containing nutrient agar. After incubation at $37^{\circ} \mathrm{C}$ for $24 \mathrm{~h}$, the number of colonies on the plate surfaces was counted. Sterilized water was used as the negative control and kanamycin $(0.05 \mathrm{mg} / \mathrm{mL})$ as the positive control. The susceptibility of ETEC K88 to the sulfated galactans was also validated using the liquid turbidity method. During the logarithmic growth period, the ETEC K88 was centrifuged, after which it was diluted to a concentration of $10^{6} \mathrm{CFU} / \mathrm{mL}$ with normal saline water. Then, $1.6 \mathrm{~mL} \mathrm{LB}$ medium, $2.0 \mathrm{~mL}$ polysaccharide solution, and $400.0 \mu \mathrm{L}$ ETEC K88 suspension were mixed in each tube. The final polysaccharide concentrations were 2.0, 4.0, 6.0, 8.0, and $10 \mathrm{mg} / \mathrm{mL}$, respectively. After incubation at $37^{\circ} \mathrm{C}$ for $24 \mathrm{~h}$, the absorbance was obtained at $600 \mathrm{~nm}$ using a microplate reader (TECAN Infinite 200 PRO, Grödig, Austria).

\subsection{MIC and $M B C$}

The MIC and MBC of D-ESP and D-GSP were performed as described by the National Committee for Clinical Laboratory Standards [25], with slight modifications. The MIC was determined as the lowest polysaccharide concentration at which no bacterial growth was detected after an incubation period of $24 \mathrm{~h}$, while the MBC represented the lowest of test polysaccharide concentration that showed no growth in the culture after incubation at $37^{\circ} \mathrm{C}$ for $48 \mathrm{~h} \mathrm{[11].} \mathrm{The} \mathrm{polysaccharides} \mathrm{were} \mathrm{dissolved}$ in sterilized $0.85 \% \mathrm{NaCl}$ saline at a concentration of $50 \mathrm{mg} / \mathrm{mL}$. The serial polysaccharide dilutions (25.0, 12.5, 10.0, 8.0, 6.25, 3.13, and $1.56 \mathrm{mg} / \mathrm{mL}$ ) were prepared for both MIC and MBC tests, which were performed in LB culture with an inoculum of about $10^{6} \mathrm{CFU} / \mathrm{mL}$. A series of tube dilutions was incubated on a rotary shaker at $180 \mathrm{rpm} / \mathrm{min}$ for either 24 or $48 \mathrm{~h}$ at $37^{\circ} \mathrm{C}$. Kanamycin solution $(0.05 \mathrm{mg} / \mathrm{mL})$ was used as the positive control and sterilized $0.85 \% \mathrm{NaCl}$ saline was used as the negative control. 


\subsection{Observation of the Sulfated Polysaccharides Entering the Bacterial Cells}

\subsubsection{Fluorescent Labeling of the Sulfated Polysaccharides}

The fluorescence-labeled sulfated polysaccharides were prepared using the reductive amination method [23]. Here, $2 \mathrm{mg}$ of either D-ESP or D-GSP were weighed and dissolved in $200 \mu \mathrm{L}$ of $1.0 \mathrm{~mol} / \mathrm{L}$ $\mathrm{NaCNBH}_{3}$ solution in a centrifuge tube. Then, $200 \mu \mathrm{L}$ of $5 \mathrm{~g} / \mathrm{L} 2$-AMAC acetic acid/DMSO $(3 / 17, v / v)$ solution were added to the system. After reacting in a water bath at $90{ }^{\circ} \mathrm{C}$ in the dark for $30 \mathrm{~min}$, the mixture was immediately stored at $-20^{\circ} \mathrm{C}$ to terminate the reaction. The free 2-AMAC in the polysaccharide mixture was extracted with a tetrahydrofuran solution, and the precipitates were collected after centrifugation ( $5000 \mathrm{r} / \mathrm{min}$ ) at $4{ }^{\circ} \mathrm{C}$ for $15 \mathrm{~min}$. This process was repeated at least four times until no 2-AMAC was detectable in the extraction solution. The 2-AMAC levels in the extraction solution were analyzed using a fluorescence microscope $(1 \times 51$, Olympus Corporation, Tokyo, Japan $)$ at 450 (excitation) and $520 \mathrm{~nm}$ (emission). The fluorescence-labeled polysaccharide solutions were lyophilized and stored at $4{ }^{\circ} \mathrm{C}$ in the dark.

\subsubsection{Fluorescence Microscope Observations}

The fluorescence-labeled or fluorescence-free sulfated polysaccharides were added into the bacterial suspension of ETEC K88 at the MIC concentration. Then, the bacterial suspension was incubated at $37^{\circ} \mathrm{C}$ in the dark for $30 \mathrm{~min}$, after which it was centrifuged at $5000 \mathrm{rpm}$ for $15 \mathrm{~min}$, and the microorganisms were washed three times with $\mathrm{pH}$ 7.4 Phosphate-Buffered Saline (PBS). Then, $5 \mu \mathrm{L}$ of the bacterial suspension were fixed on a microscope slide and observed using a fluorescence microscope $(1 \times 51$, Olympus Corporation, Tokyo, Japan) at 450 (excitation) and $520 \mathrm{~nm}$ (emission).

\subsection{Observation of the Cell Membrane Permeability}

The fluorescent probe PI was used to detect the membrane integrity according to an earlier study [24]. The ETEC K88 bacterial solution in the logarithmic growth phase was centrifuged, and the obtained bacteria were washed twice with PBS ( $\mathrm{pH} 7.4$ ) and resuspended at about $10^{8} \mathrm{CFU} / \mathrm{mL}$. Then, the polysaccharide samples were added at final concentrations of $1 \mathrm{MIC}$ and 2MIC. After incubation at $37^{\circ} \mathrm{C}$ for $2 \mathrm{~h}$, the bacterial cells were collected via centrifugation $(5000 \mathrm{r} / \mathrm{min} \times 15 \mathrm{~min})$, and the cells were washed twice with PBS (pH 7.4). Then, the bacteria were resuspended in pH 7.4 PBS at $10^{8} \mathrm{CFU} / \mathrm{mL}$. The fluorescent probe PI was added to the bacterial suspension at a final concentration of $20.0 \mu \mathrm{mol} / \mathrm{L}$ and left to react at $37^{\circ} \mathrm{C}$ in the dark for $20 \mathrm{~min}$. Then, $5.0 \mu \mathrm{L}$ of the bacterial suspension were fixed on a microscope slide and examined using a fluorescence microscope (RVL-100-G, ECHO, San Diego, CA, USA) at $488 \mathrm{~nm}$ (excitation) and $640 \mathrm{~nm}$ (emission).

\subsection{Leakage of Intracellular Protein}

The permeability of the cell membrane was determined by detecting the intracellular protein leakage in the culture medium [27]. The ETEC K88 bacterial solution in the logarithmic growth period was centrifuged, and the obtained cells were washed twice with PBS (pH 7.4). The microbes were resuspended in pH 7.4 PBS, while the optical density of the suspension was adjusted to 2.0. Then, the polysaccharide samples were added at a $1 \mathrm{MBC}$ concentration, after which the bacterial suspensions were incubated at $37^{\circ} \mathrm{C}$ for 1,3 , and $5 \mathrm{~h}$. After centrifugation $5000 \mathrm{r} / \mathrm{min}$ for $15 \mathrm{~min}$, the supernatants were collected, concentrated ten times, and analyzed using SDS-PAGE gel electrophoresis.

\subsection{The Effect of Sulfated Polysaccharides on the Growth of Different Microorganisms}

The sulfated polysaccharides (D-ESP and D-GSP) were added to the culture medium containing different microorganisms at the concentration of MBC to ETEC K88, including intestinal probiotics (Lactobacillus rhamnosus ATCC 53103, Bacillus coagulans ATCC 7050, and Bacillus subtilis CMCC 63501), S. aureus ATCC 29213, and Saccharomyces cerevisiae BY4741. After $16 \mathrm{~h}$ of co-culturing the 
polysaccharides with different microorganisms, their growth was examined at $2 \mathrm{~h}$ intervals by determining the absorbance of the culture medium at $600 \mathrm{~nm}$.

\subsection{Statistical Analysis}

The statistical significance of the differences between the control and treatment groups was determined with one-way ANOVA using Origin version 8.0 (OriginLab Corporation, Northampton, MA, USA), followed by Tukey tests. A normality test showed that all the raw data displayed normal distribution, while a variance test indicated that all groups exhibited equal variance. Data are expressed as mean $\pm \mathrm{SD}$ of at least three individual experiments, each performed in triplicate. $p<0.05$ was considered statistically significant.

\section{Conclusions}

Two types of sulfated galactans, namely ESP and GSP, were obtained from E. serra and G. verrucosa, respectively. After metal ion desorption and depolymerization, the improved anti-ETEC K88 activity of D-ESP and D-GSP was revealed, confirming that these sulfated polysaccharides can penetrate the cell membranes of ETEC K88 and eventually reach the cell interior, leading to the destruction of cell membrane permeability and integrity. Furthermore, D-ESP and D-GSP can selectively inhibit the proliferation of ETEC K88, but not the selected Gram-positive bacteria and yeast. This study implies that the low-MW sulfated galactans from marine red algae may display potential application value for the treatment of bacterial diarrhea.

Author Contributions: Designed research, Y.L.; data curation, Y.M. and Z.C.; formal analysis, Y.W.; investigation, L.H.; methodology, C.Z. and D.L.; project administration, Y.L.; writing-original draft, Y.M. and W.L.; writing-review and editing, M.-J.C.; supervision, G.-M.L. All authors have read and agreed to the published version of the manuscript.

Funding: This research was funded by the National Key R\&D Program of China (grant number: 2019YFC1605003-3) and Science and Technology Projects of Xiamen Science and Technology Bureau (grant number: 3502Z20183034).

Conflicts of Interest: The authors declare no conflict of interest.

\section{References}

1. Ruan, X.; Zhang, W. Oral immunization of a live attenuated Escherichia coli strain expressing a holotoxin-structured adhesin-toxoid fusion (1FaeG-FedF-LTA2:5LTB) protected young pigs against enterotoxigenic E. coli (ETEC) infection. Vaccine 2013, 31, 1458-1463. [CrossRef]

2. Walker, R.I. An assessment of enterotoxigenic Escherichia coli and Shigella vaccine candidates for infants and children. Vaccine 2015, 33, 954-965. [CrossRef]

3. Zhang, H.; Xu, Y.; Zhang, Z.; You, J.; Yang, Y.; Li, X. Protective immunity of a Multivalent Vaccine Candidate against piglet diarrhea caused by enterotoxigenic Escherichia coli (ETEC) in a pig model. Vaccine 2018, 36, 723-728. [CrossRef]

4. $\quad$ Li, S.; Qi, Y.; Chen, L.; Qu, D.; Li, Z.; Gao, K.; Chen, J.; Sun, Y. Effects of Panax ginseng polysaccharides on the gut microbiota in mice with antibiotic-associated diarrhea. Int. J. Biol. Macromol. 2019, 124, 931-937. [CrossRef]

5. Ropellato, J.; Carvalho, M.M.; Ferreira, L.G.; Noseda, M.D.; Zuconelli, C.R.; Gonçalves, A.G.; Ducatti, D.R.B.; Kenski, J.C.N.; Nasato, P.L.; Winnischofer, S.M.B.; et al. Sulfated heterorhamnans from the green seaweed Gayralia oxysperma: Partial depolymerization, chemical structure and antitumor activity. Carbohydr. Polym. 2015, 117, 476-485. [CrossRef]

6. Cui, M.; Wu, J.; Wang, S.; Shu, H.; Zhang, M.; Liu, K.; Liu, K. Characterization and anti-inflammatory effects of sulfated polysaccharide from the red seaweed Gelidium pacificum Okamura. Int. J. Biol. Macromol. 2019, 129, 377-385. [CrossRef]

7. Yang, Y.; Liu, D.; Wu, J.; Chen, Y.; Wang, S. In vitro antioxidant activities of sulfated polysaccharide fractions extracted from Corallina officinalis. Int. J. Biol. Macromol. 2011, 49, 1031-1037. [CrossRef] 
8. Sanjeewa, K.K.A.; Kang, N.; Ahn, G.; Jee, Y.; Kim, Y.-T.; Jeon, Y.-J. Bioactive potentials of sulfated polysaccharides isolated from brown seaweed Sargassum spp in related to human health applications: A review. Food Hydrocoll. 2018, 81, 200-208. [CrossRef]

9. Tziveleka, L.-A.; Ioannou, E.; Roussis, V. Ulvan, a bioactive marine sulphated polysaccharide as a key constituent of hybrid biomaterials: A review. Carbohydr. Polym. 2019, 218, 355-370. [CrossRef]

10. Thangapandi, M.; Kumar, T. Antibacterial effect of fucoidan from Sargassum wightii against the chosen human bacterial pathogens. Int. Curr. Pharm. J. 2013, 2, 156-158.

11. Liu, M.; Liu, Y.; Cao, M.; Liu, G.; Chen, Q.; Sun, L.; Chen, H. Antibacterial activity and mechanisms of depolymerized fucoidans isolated from Laminaria japonica. Carbohydr. Polym. 2017, 172, 294-305. [CrossRef]

12. Pierre, G.; Sopena, V.; Juin, C.; Mastouri, A.; Graber, M.; Maugard, T. Antibacterial activity of a sulfated galactan extracted from the marine alga Chaetomorpha aerea against Staphylococcus aureus. Biotechnol. Bioproc. Eng. 2011, 16, 937-945. [CrossRef]

13. Liu, B.; Liu, Q.-M.; Li, G.-L.; Sun, L.-C.; Gao, Y.-Y.; Zhang, Y.-F.; Liu, H.; Cao, M.-J.; Liu, G.-M. The anti-diarrhea activity of red algae-originated sulphated polysaccharides on ETEC-K88 infected mice. RSC Adv. 2019, 9, 2360-2370. [CrossRef]

14. Liu, X.; Xia, W.; Jiang, Q.; Yu, P.; Yue, L. Chitosan oligosaccharide-N-chlorokojic acid mannich base polymer as a potential antibacterial material. Carbohydr. Polym. 2018, 182, 225-234. [CrossRef]

15. Rabea, E.; Badawy, M.; Stevens, C.; Smagghe, G.; Steurbaut, W. Chitosan as antimicrobial agent: Applications and mode of action. Biomacromolecules 2003, 4, 1457-1465. [CrossRef]

16. Rostand, K.S.; Esko, J.D. Microbial adherence to and invasion through proteoglycans. Infect. Immun. 1997, 65, 1-8. [CrossRef]

17. Porse, H.; Rudolph, B. The seaweed hydrocolloid industry: 2016 updates, requirements, and outlook. J. Appl. Phycol. 2017, 29, 2187-2200. [CrossRef]

18. Liu, Y.; Liu, W.; Wang, Y.; Ma, Y.; Huang, L.; Zou, C.; Li, D.; Cao, M.; Liu, G. Inhibitory effect of depolymerized sulfated galactans from marine red algae on the growth and adhesion of diarrheagenic Escherichia coli. Mar. Drugs 2019, 17, 694. [CrossRef]

19. Paz, S.; Rubio, C.; Frias, I.; Gutierrez, A.J.; Gonzalez-Weller, D.; Martin, V.; Revert, C.; Hardisson, A. Toxic metals ( $\mathrm{Al}, \mathrm{Cd}, \mathrm{Pb}$ and $\mathrm{Hg}$ ) in the most consumed edible seaweeds in Europe. Chemosphere 2019, 218, 879-884. [CrossRef]

20. Abu, R.; Jiang, Z.; Ueno, M.; Okimura, T.; Yamaguchi, K.; Oda, T. In vitro antioxidant activities of sulfated polysaccharide ascophyllan isolated from Ascophyllum nodosum. Int. J. Biol. Macromol. 2013, 59, 305-312. [CrossRef]

21. Fan, M.; Sun, X.; Qian, Y.; Xu, Y.; Wang, D.; Cao, Y. Effects of metal ions in tea polysaccharides on their in vitro antioxidant activity and hypoglycemic activity. Int. J. Biol. Macromol. 2018, 113, 418-426. [CrossRef]

22. Tokura, S.; Ueno, K.; Miyazaki, S.; Nishi, N. Molecular weight dependent antimicrobial activity by chitosan. Macromol. Sym. 1997, 120, 1-9. [CrossRef]

23. Okafo, G.; Langridge, J.; North, S.; Organ, A.; West, A.; Morris, M.; Camilleri, P. High performance liquid chromatographic analysis of complex N-linked glycans derivatized with 2-aminoacridone. Anal. Chem. 1997, 69, 4985-4993. [CrossRef]

24. He, F.; Yang, Y.; Yang, G.; Yu, L. Studies on antibacterial activity and antibacterial mechanism of a novel polysaccharide from Streptomyces virginia H03. Food Control 2010, 21, 1257-1262. [CrossRef]

25. Kolsi, R.B.A.; Salah, H.B.; Jardak, N.; Chaaben, R.; Jribi, I.; Feki, A.E.; Rebai, T.; Jamoussi, K.; Allouche, N.; Blecker, C.; et al. Sulphated polysaccharide isolated from Sargassum vulgare: Characterization and hypolipidemic effects. Carbohyd. Polym. 2017, 170, 148-159. [CrossRef]

26. Engel, H.; Smink, A.J.; Vanwijngaarden, L.; Keck, W. Murein-metabolizing enzymes from Escherichia coli: Existence of a second lytic transglycosylase. J. Bacteriol. 1992, 174, 6394-9403. [CrossRef]

27. Zhang, Y.; Wu, Y.; Zheng, W.; Han, X.; Jiang, Y.; Hu, P.; Tang, Z.; Shi, L. The antibacterial activity and antibacterial mechanism of a polysaccharide from Cordyceps cicadae. J. Funct. Foods 2017, 38, 273-279. [CrossRef]

28. Malanovic, N.; Lohner, K. Gram-positive bacterial cell envelopes: The impact on the activity of antimicrobial peptides. BBA Biomembr. 2016, 1858, 936-946. [CrossRef]

29. Tang, C.; Xie, B.; Sun, Z. Antibacterial activity and mechanism of B-type oligomeric procyanidins from lotus seedpod on enterotoxigenic Escherichia coli. J. Funct. Foods 2017, 38, 454-463. [CrossRef] 
30. Böttcher, T.; Szamosvári, D.; Clardy, J. A repeating sulfated galactan motif resuscitates dormant Micrococcus luteus bacteria. Appl. Environ. Microbiol. 2018, 84, e00745-e00818. [CrossRef]

31. Li, S.; Yang, X.; Ma, H.; Yan, J.; Guo, D. Purification, characterization and antitumor activity of polysaccharides extracted from Phellinus igniarius mycelia. Carbohydr. Polym. 2015, 133, 24-30. [CrossRef]

32. Liu, Y.; Liu, Z.; Ji, B.; Wu, Y. Methods of removing heavy metals for extracting and purifying fucoidans from brown seaseeds. Food Sci. 2010, 31, 1-5. (In Chinese) [CrossRef]

33. Badrinathan, S.; Shiju, T.M.; Sharon Christa, A.S.; Arya, R.; Pragasam, V. Purification and structural characterization of sulfated polysaccharide from Sargassum myriocystum and its efficacy in scavenging free radicals. Indian J. Pharm. Sci. 2012, 74, 549-555.

34. Schafer, H.N.S. An improved spectrophotometric method for determination of sulfate with barium chloranilate as applied to coal ash and related materials. Anal. Chem. 1967, 39, 1719-1726. [CrossRef]

35. Lin, Y.; Yang, Z.; Yang, N.; Zhang, Y.; Zhou, X.; Fan, Y. Content analysis of metal elements in sodium alginate. J. Qingdao Univ. Nat. Sci. Ed. 2018, 31, 35-39. (In Chinese)

36. Chen, W.; Cheng, F.; Swing, C.J.; Xia, S.; Zhang, X. Modulation effect of core-wall ratio on the stability and antibacterial activity of cinnamaldehyde liposomes. Chem. Phys. Lipids 2019, 223, 104790. [CrossRef]

37. Lin, L.; Zhu, Y.; Li, C.; Liu, L.; Surendhiran, D.; Cui, H. Antibacterial activity of PEO nanofibers incorporating polysaccharide from dandelion and its derivative. Carbohydr. Polym. 2018, 198, 225-232. [CrossRef]

(C) 2020 by the authors. Licensee MDPI, Basel, Switzerland. This article is an open access article distributed under the terms and conditions of the Creative Commons Attribution (CC BY) license (http://creativecommons.org/licenses/by/4.0/). 